\title{
Study of the Relation between Sediment Characteristics and Multiphase Flow to the Presence of Sediment Oxygen Demand (SOD) in Open Channels
}

\author{
Dhimas Dwinandha ${ }^{1 *}$, and Haryo Satriyo Tomo $^{2}$ \\ ${ }^{1,2}$ Department of Environmental Engineering, Institut Teknologi Bandung, Jalan Ganesha No.10 Bandung 40132, Indonesia
}

\begin{abstract}
A laboratory study was conducted with the aim to determine the correlation between sediment characteristics and multiphase flow analysis of carrier fluid to the presence of SOD. Six sediment samples were tested on their physical and chemical characteristics along with particle size distribution of sediments to find the indication of oxygen consumption and to classify the soil sediment class. For multiphase flow analysis, there were two transition velocities calculated: the transition between a pseudo-homogenous flow and a heterogeneous flow and the limit deposit velocities at the onset of solid particle bed. The SOD test was done in laboratory-scale by using a $600-\mathrm{mL}$ reactor. According to tests, the amount of organic carbon content (TOC) in the samples were ranging from 34.58 to $81.27 \%$, with the sediments' textures categorised as silt loam, silty clay loam, and sand. In the channels, heterogeneous flow occurred in two channel segments, while the other segments' regime was classified as homogeneous flow. The obtained SOD values were varied from 0.2427 to $0.8487 \mathrm{~g} / \mathrm{m} 2 /$ day with $\mathrm{K} 3$ values obtained ranged from 8.6537 to $12.4028 \mathrm{~m}-1$. Based on all analysis, the organic characteristic of sediment holds a key role in the presence of SOD value.
\end{abstract}

\section{Introduction}

SOD is the rate at which DO is removed from the overlying water column by biochemical processes in the streambed sediments [5]. SOD includes oxygen consumption of biological activity (e.g. by microorganisms in the sediment) and chemical oxidation reactions to certain chemical species, including $\mathrm{Fe}^{2+}$, $\mathrm{Mn}^{2+}$, and $\mathrm{S}^{2-}[6]$.

Research on the SOD is not a new in determining water quality. Rounds and Doyle [8] found that the rate of SOD by 1-4 g/m2/day (typical SOD value of sandy sediments with little organic material) was still high enough to be an important component in a DO depletion. Seiki, et al [9] found the similar result that a minute amount of biodegradable organic compound in the sandy environment could also consume oxygen significantly. The decrease in concentration DO can cause a condition called hypoxia (DO $<2 \mathrm{mg} / \mathrm{L}$ ) and anoxia (no DO at all) that can affect aquatic ecology and human population due to the loss of resources and water pollution [7].

Based on the explanation above, conducting a research about SOD is advantageous for several purposes. First, it can be used to develop mathematical models for predicting the allocation of water pollution load. In addition, this study can be a basis for planning the revitalization of the open channel, either natural or artificial channel. This study, however, was focusing on the relation between sediment characteristics and multiphase flow to the existence of SOD in open channels in Indonesia, particularly in the Province of West Java. This study is expected to be a trigger for conducting the other research related to the SOD in Indonesia, so there will be more references about sediment and its effect to the water ecosystem.

\section{Methodology}

\subsection{Sampling and Field Observation}

Six sediment samples from six channel segments were collected and tested in this study. Sampling sites located in the Citarum River (Kota Baru Parahyangan, Buah Batu, and downstream to Saguling Reservoir segment), Citarik River (downstream to the Citarum River segment), Cikapundung River (upstream segment), and West Tarum Channel (downstream near the Cikeas River segment). The sample number that corresponds to the sampling location is given in Table 1. Sediment samples were collected using sediment grab method and sealed in plastic bags. All the samples were stored and kept in a cool box. DO concentrations of each segments were also measured to be defined as DO target in SOD measurement.

\footnotetext{
* Corresponding author: author@e-mail.org
} 
Table 1. Sampling location.

\begin{tabular}{|c|l|}
\hline No. & \multicolumn{1}{|c|}{ Sampling Location } \\
\hline 1 & Citarum River (Kota Baru Parahyangan) \\
\hline 2 & Citarum River (Buah Batu) \\
\hline 3 & Citarum River (Saguling Reservoir) \\
\hline 4 & Citarik River \\
\hline 5 & Cikapundung River \\
\hline 6 & West Tarum Channel (WTC) \\
\hline
\end{tabular}

\subsection{Sediment Characteristic Tests}

There were physical and chemical characteristic test conducted as sediment characterisation. Tests of physical characteristics were carried out in Soil Mechanics Laboratory of Civil Engineering Programme ITB. The test included densities (bulk and dry density), water content, and particle size distribution. TOC test method, as a chemical property of sediment samples, was based on the principles of FAS titration toward the excess potassium dichromate (K2Cr2O7) while being destructed under acidic conditions and heat. The testing was done twice (duplo) to obtain more accurate and precise results.

\subsection{Multiphase Flow Calculation}

Multiphase flow analysis was conducted to observe the behaviour of flow occurred above the sediment. The analysis included settling velocity and flow regime determination. Settling velocity (vs) was calculated using Equation [1], initiated by assuming CD value, calculating Reynolds number, and then calculating vs value. Iteration was stopped when the calculation result was convergent (less than $10^{-4}$ error).

$$
v_{s}=\sqrt{\frac{4}{3} \cdot \frac{g \cdot d}{C_{d}}\left(\frac{\rho_{p}-\rho_{w}}{\rho_{w}}\right)}
$$

Determination of flow regime was done by using Equation [2] developed by Newitt, et al. (written in Giguere, et al. [3]) to differentiate between the pseudohomogenous and heterogeneous flow, while to separate between heterogeneous and stationary bed flow, Equation [3] and [4] were used [3].

$$
\begin{gathered}
v_{L H}=\left(1800 \cdot g \cdot d \cdot v_{s}\right)^{1 / 3} \\
v_{L D}=F_{L D}\left[2 \cdot g \cdot d \cdot\left(\frac{\rho_{p}-\rho_{w}}{\rho_{w}}\right)\right]^{1 / 2} \\
F_{L D}=2+0,3 \cdot \log _{10}\left(\frac{d}{D \cdot C_{D}}\right)
\end{gathered}
$$

The value of $V_{L H}$ and $V_{L D}$ was compared to the flow velocity in the observed channel. Pseudo-homogenous flow occurred if $\mathrm{v}_{\text {flow }}>\mathrm{V}_{\mathrm{LH}}$, heterogenous flow occurred if $\mathrm{V}_{\mathrm{LH}}>\mathrm{V}_{\text {flow }}>\mathrm{V}_{\mathrm{LD}}$, and stationary bed condition occurred if $\mathrm{V}_{\mathrm{LD}}>\mathrm{v}_{\text {flow. }}$.

\subsection{SOD Measurement}

SOD was assessed in laboratory scale by measuring oxygen depletion over time. DO concentrations were measured every 10 minutes, 30 minutes, 60 minutes, and 120 minutes until DO concentration remained constant (steady). The reactor used in the test was $600 \mathrm{~mL}$ reactor as shown in Figure 1.

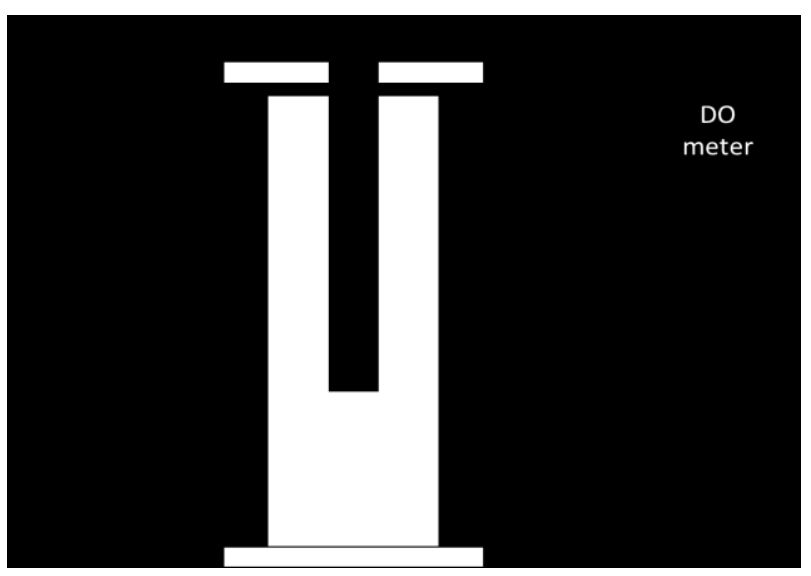

Fig. 1. SOD test reactor design.

SOD test was started by filling aquadest to the reactor that had been filled with approximately $300 \mathrm{~mL}$ sediment until full. The DO meter probe then mounted on the lid of the reactor, and then that set of the lid was used to seal the reactor until there were no more air exchanges, both from inside and outside the reactor. The equation used to determine the SOD value was derived from Gin, et al. [4], which is showed in Equation [5]. The obtained SOD value then corrected by temperature using Equation [6].

$$
\begin{gathered}
S O D=\frac{\left(1000 \cdot \frac{V}{A} \cdot\left(C_{f}-C_{i}\right)\right)}{\Delta t} \\
(S O D)_{20}=\frac{(S O D)_{T}}{\theta^{(T-20)}}
\end{gathered}
$$

\subsection{Determination of Deoxygenation Coefficient $\left(K_{3}\right)$}

Determination of deoxygenation coefficient due to SOD (K3) was done by: (a) calculating the SOD value; (b) determining the regression equation of the obtained DO decline profile; (c) conducting simple linear correlation test to determine the significance of the regression equation; and (d) calculating $\mathrm{K}_{3}$. Determination of the regression equation was performed by using Microsoft Excel. DO concentration was defined as variable $\mathrm{X}$ and time as variable $\mathrm{Y}$. In addition, determinant coefficient value $\left(\mathrm{R}^{2}\right)$ was taken, as well, for simple linear correlation analysis tests. After the statistical test, the $\mathrm{K}_{3}$ value was calculated using Equation (7) adapted from the general equation of the first order reaction.

$$
K_{3}=\frac{\left(\frac{\left.{ }_{{ }_{\text {initial }}-C_{\text {final }}}\right)}{\Delta t}\right)}{S O D}
$$




\section{Result and Discussion}

\subsection{Particle Size Distribution}

The sediment size composition or distribution is showed in Figure 2. The data indicates that most of the particle size in the sediment sample was silt, except sample 5 (Cikapundung River), which dominated by the sand. Distribution of particles in sample 5 caused by the sample was taken in the upper reach of the river with high flow velocity, so the smaller particles had not been formed yet or had been washed out. On the contrary, other sampling locations had a low flow velocity. That condition allowed the sedimentation of suspended particles in water, therefore the range of particle size was larger.

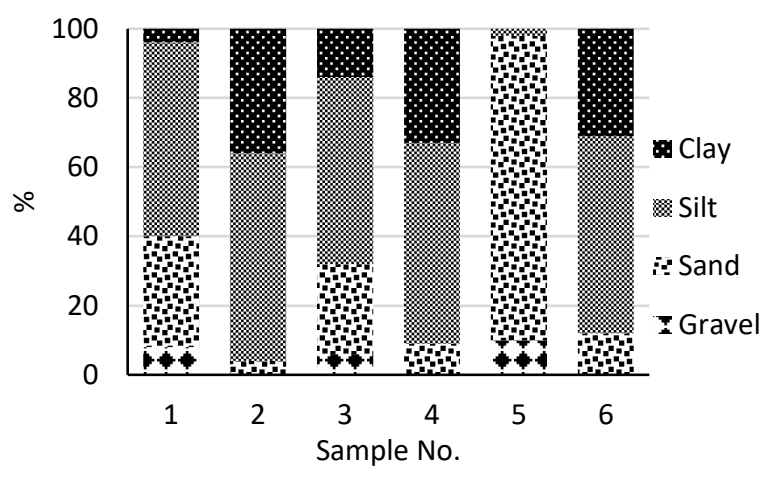

Fig. 2. Distribution of sediment particle size.

The plot of particle size composition in soil texture triangle according to USDA (US Department of Agriculture) is illustrated in Figure 3. The figure reveals that the sample 1 and 3 was categorised as silt loam soil, the class of sample 2, 4, and 6 are silty clay loam, and sample 5 classified as sand, as expected.

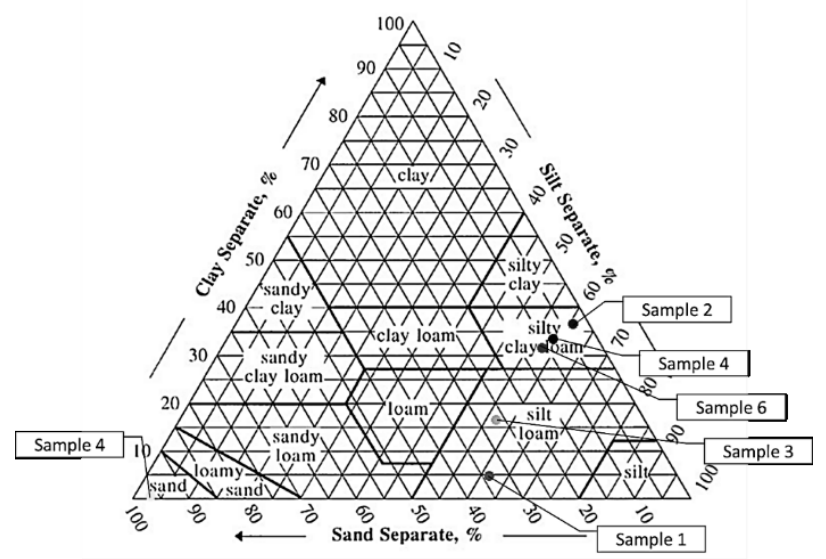

Fig. 3. Soil texture triangle for sediment samples.

\subsection{Index Properties of Sediment}

Index properties of the observed sediment samples (water content along with bulk and dry density) are given in Table 2 .
Table 2. Index properties of sediment samples.

\begin{tabular}{|c|r|r|r|}
\hline No. & $\begin{array}{c}\gamma_{\mathrm{m}} \\
\left(\mathrm{kN} / \mathrm{m}^{3}\right)\end{array}$ & $\begin{array}{c}\gamma_{\mathrm{d}} \\
\left(\mathrm{kN} / \mathrm{m}^{3}\right)\end{array}$ & $\begin{array}{c}\text { Wn } \\
(\%)\end{array}$ \\
\hline 1 & 15,40 & 9,30 & 66 \\
\hline 2 & 13,70 & 6,33 & 116 \\
\hline 3 & 15,20 & 9,07 & 68 \\
\hline 4 & 13,40 & 5,81 & 131 \\
\hline 5 & 17,20 & 11,89 & 45 \\
\hline 6 & 13,60 & 6,76 & 101 \\
\hline
\end{tabular}

The result reveals that the sediment in Cikapundung River (sample 5) had the highest density, while the Citarik River sediment (sample 4) had the lowest compared to other samples. The magnitude of particle density of the sediment could be influenced by the chemical composition of the sediments. The higher amount of mineral content in the sediment (commonly found in sand particles) is, the denser the sediment will be. Meanwhile, the density of sediment will be low if the composition of the sediments mostly contains light organic compounds, as found in clay and silt particles.

The data showed that the sediments were highly saturated by water. High water content could be resulted by sediment particle size composition dominated by clay and/or silt. Clay and silt have a high adhesion force that can accommodate and retain water, resulting in high water holding capacity of the sediment. On the other hand, sand particle has a low adhesion force, thus the water tends to be escaped when passed through a sand layer.

\subsection{Total Organic Carbon (TOC) Content}

The presence of organic carbon might indicate the consumption of dissolved oxygen in the water body because organic carbon is a source of energy for the microorganisms. Table 3 gives the test result of total organic carbon content (TOC) in sediment samples taken.

Table 3. Percentage of total organic carbon (TOC) in sediment.

\begin{tabular}{|c|c|}
\hline No & TOC (\%) \\
\hline 1 & 46,44 \\
\hline 2 & 49,84 \\
\hline 3 & 81,27 \\
\hline 4 & 54,64 \\
\hline 5 & 37,63 \\
\hline 6 & 34,58 \\
\hline
\end{tabular}

Sediment in Citarum River-Reservoir Saguling had the highest percentage of total organic carbon (TOC) content with $81.27 \%$. The high amount of TOC could be caused by organic compounds accumulation from previous river segments. In addition, the particle size composition that dominated by silt and clay particles made high level of organic carbon compounds were adsorbed from the water. 
The sample with the lowest percentage of TOC was a sample 6 (West Tarum Channel). This might be due to the low concentration of suspended organic compounds found in the water, hence only few solid particles containing organic compounds settled to the bottom of the channel. As the result, less oxygen consumption would be occurred in the channel.

There was a large variation of concentrations in each sample that can be caused by the significant difference in location sampling. Besides, the level of pollution of the water body at sampling locations can also affect the amount of TOC percentage in the sediment.

\subsection{Settling Velocity of Sediment Particles}

Sediment settling velocity calculated using the cut size diameter $\left(d_{50}\right)$ of the sediment. The result of the settling velocity calculation is shown in Table 4 . Five of six samples have $\mathrm{d}_{50}$ included in the range of $0.002-0.05 \mathrm{~mm}$, which indicated that the particle was classified as silt. Only sample 5 (Cikapundung River) that have $\mathrm{d}_{50}$ on the sand category (range of $0.05-2.00 \mathrm{~mm}$ ).

Table 4. Settling velocity of sediment particle.

\begin{tabular}{|c|c|c|}
\hline No. & $\begin{array}{c}\mathrm{d}_{50} \\
(\mathrm{~mm})\end{array}$ & $\begin{array}{c}\mathrm{v}_{\mathrm{s}} \\
(\mathrm{m} / \mathrm{s})\end{array}$ \\
\hline 1 & 0,0650 & 0,01458 \\
\hline 2 & 0,0079 & 0,00677 \\
\hline 3 & 0,0400 & 0,01198 \\
\hline 4 & 0,0100 & 0,00684 \\
\hline 5 & 0,3700 & 0,05070 \\
\hline 6 & 0,0140 & 0,00753 \\
\hline
\end{tabular}

The settling velocity was the parameter that is directly associated to the size and density of the particles. This showed that the settling velocity of particles would increase in line with the increasing of particle diameter and mass. This phenomenon could be seen in the data provided in Table 3. Sample 5 (Cikapundung River) has the highest settling velocity due to the largest diameter and highest density.

\subsection{Slurry Flow Regime}

The calculation result in determining slurry flow regime is shown in Table 5. There were two types of flow regime in observed channels, which were homogeneous (samples $1,2,4$, and 5) and heterogeneous (3 and 6). The difference of this regime can be explained by the variation in flow velocity of the carrier fluid and the turbulence of the flow as the effects of the flow velocity.
Table 5. Slurry flow regimes.

\begin{tabular}{|c|c|c|c|c|}
\hline No. & $\begin{array}{c}\text { VLH } \\
(\mathrm{m} / \mathrm{s})\end{array}$ & $\begin{array}{c}\text { VLD } \\
(\mathrm{m} / \mathrm{s})\end{array}$ & $\begin{array}{c}\text { Vflow } \\
(\mathrm{m} / \mathrm{s})\end{array}$ & Flow Regime \\
\hline 1 & 0,25576 & 0,01717 & 0,3942 & Homogenous \\
\hline 2 & 0,09811 & 0,00231 & 0,6722 & Homogenous \\
\hline 3 & 0,20375 & 0,01094 & 0,0178 & Heterogenous \\
\hline 4 & 0,10652 & 0,00292 & 0,1429 & Homogenous \\
\hline 5 & 0,69190 & 0,07698 & 1,2800 & Homogenous \\
\hline 6 & 0,12301 & 0,00380 & 0,1197 & Heterogenous \\
\hline
\end{tabular}

Multiphase flow regime can show the difference of solid concentration distribution in a carrier fluid. Heterogeneous flow regime indicates that there are more particles at the base of the channel than in the middle or in the surface. It showed a strong cohesion force between particles of sediment at the bottom of the channel so that the carrier fluid flow has a little effect on sediment particles movement.

On the contrary, homogeneous flow shows the concentration of solids evenly distributed, thus resulting in similar concentration of solids throughout the flow. Unlike heterogeneous regime, the cohesion force between sediment particles is weak, but the adhesion force between sediment particles with water is strong, therefore the solid particles move followed by the water as carrier fluid. Additionally, lightweight sediment particles (small diameter or low density) can also lead to the occurrence of a homogeneous flow regime because lightweight sediment particles have low settling velocity. However, the flow velocity of carrier fluid has a greater influence than the setting velocity of the particle. The statement can be proved by looking at the data for sample 5 (Cikapundung River), which had the highest settling velocity among other samples but its flow regime was homogeneous.

The process of sedimentation in a homogeneous flow regime should not have occurred because the solid particles are carried away until the flow regime changes by the flow velocity difference. The presence of sediment in sampling location indicated that there was an unnatural process of sedimentation. The unnatural sedimentation process that possibly occurred was solid particles stuck on the edge of a channel that has vegetation and was accumulated in the base of the channel.

\subsection{Sediment Oxygen Demand (SOD) Analysis}

Figure 4 depicts the dissolved oxygen (DO) concentration depletion, while Table 6 represents the calculated SOD values. 


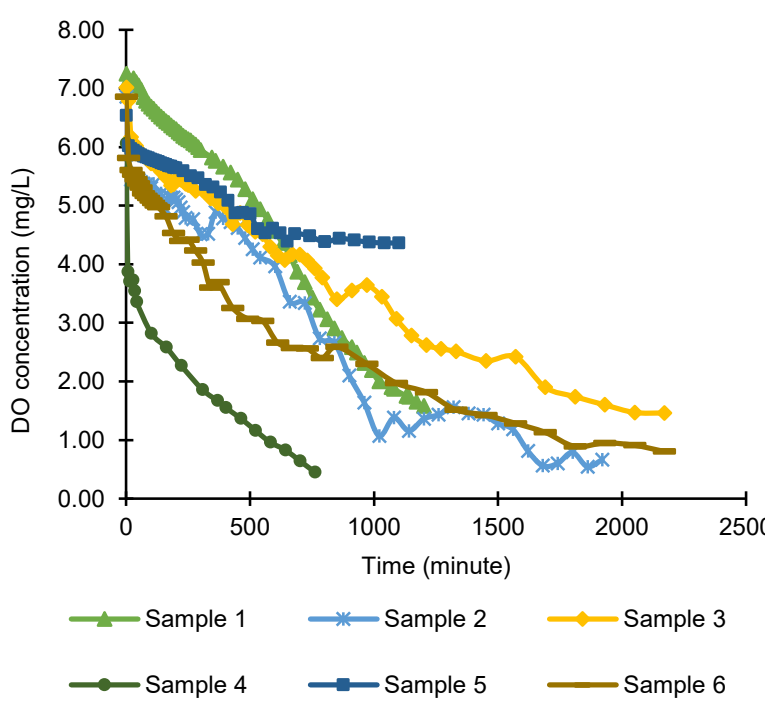

Fig. 4. DO concentration depletion profile.

Table 6. Obtained SOD values in sediment samples.

\begin{tabular}{|c|c|}
\hline No. & $\begin{array}{c}\text { SOD } @ 20^{\circ} \mathrm{C} \\
\mathrm{g} / \mathrm{m}^{2} / \text { day }\end{array}$ \\
\hline 1 & 0,5805 \\
\hline 2 & 0,3835 \\
\hline 3 & 0,3143 \\
\hline 4 & 0,8487 \\
\hline 5 & 0,2427 \\
\hline 6 & 0,3317 \\
\hline
\end{tabular}

The overall decrease in DO concentration profiles showed a similar trend, which was a substantial decrease of DO concentration in early test. According to Barcelona and Wang [1], it is most likely to occur because of the presence of chemical SOD on sediment. Chemical SOD is composed of sulfidic demand and chemical-sulfidic demand. Chemical-sulfidic demand indicates the oxidation of organic compounds and iron-manganese minerals, while sulfidic demand describes the oxidation of sulphide compound, such as $\left[\mathrm{HS}^{-}\right]$and $\left[\mathrm{S}^{2-}\right]$. Therefore, the greater decline of DO concentration at the beginning of the test, the greater chemical SOD in these sediments.

Based on the data in Table 5, it shows that the SOD value in sample 4 (Citarik River) was the highest among other samples. The high amount of SOD value can be caused by the huge amount of organic matter that can be degraded. In addition, sediment particles that categorised as silty clay loam accommodate high adsorption of organic compounds from water (especially suspended organic compounds) because of the large surface area. Another cause was the major fraction of chemical SOD presented in the sample (showed in rapid drop of DO concentration in early test).

The channel segment that had the lowest SOD value was the Cikapundung River (sample 5). This was because the sampling location laid on the upper reaches of the river with sand-class sediment particles; therefore, it is less capable of adsorbing organic content as much as in the
Citarik River sediment. The flow velocity of the river might also be the reason; while the velocity was high enough, most of the organic content in the sediment particles could be washed out and dissolved again.

Although the TOC percentage in sample 3 was the highest of the overall sample, the SOD value of the sample did not follow. This shows that the amount of degradable organic carbon compounds in the sample holds a significant role in affecting SOD value. Sample 3 might have a low amount of degradable organic compound, and so did its SOD value. The amount of degradable organic compounds can be affected by the duration of sediments present in the water. Leutheuser (written in Barcelona and Wang [1]) opined that organic compounds that have been accumulated in the sediment for a long time would react slower than the fresh organic compounds.

\subsection{Deoxygenation Coefficient due to $\operatorname{SOD}\left(\mathrm{K}_{3}\right)$}

First step in determining $\mathrm{K}_{3}$ value was conducting a statistical test called simple linear correlation analysis. This was done to observe if there was any alteration in DO concentration gradient. The alteration is important to analyse DO consumption kinetics. The complete result of the test presents in Table 7. Based on the results, it could be concluded that all regression equations were significant in $5 \%$ and $1 \%$ level. Thus, there was no change in the gradient of decreasing concentration of dissolved oxygen during testing.

After statistical tests, the calculations of $\mathrm{K}_{3}$ was performed. The results of the calculation of the value of the coefficient of deoxygenation due to SOD in samples are listed in Table 8.

Table 7. Results of simple linear correlation analysis.

\begin{tabular}{|c|c|c|c|c|c|c|}
\hline \multirow{2}{*}{ No } & \multirow{2}{*}{$\mathrm{n}$} & \multirow{2}{*}{$\mathrm{R}^{2}$} & \multirow{2}{*}{$\begin{array}{c}\mathrm{r}- \\
\text { calculated }\end{array}$} & \multicolumn{2}{|c|}{$\mathrm{r}$-table } & \multirow{2}{*}{ Conclusion } \\
\cline { 5 - 6 } & & & & $5 \%$ & $1 \%$ & \\
\hline 1 & 61 & 0,9914 & $-0,9957$ & 0,250 & 0,325 & $\begin{array}{c}\text { Significant } \\
\text { for } \alpha=1 \%\end{array}$ \\
\hline 2 & 58 & 0,9436 & $-0,9714$ & 0,260 & 0,340 & $\begin{array}{c}\text { Significant } \\
\text { for } \alpha=1 \%\end{array}$ \\
\hline 3 & 60 & 0,9624 & $-0,9810$ & 0,250 & 0,325 & $\begin{array}{c}\text { Significant } \\
\text { for } \alpha=1 \%\end{array}$ \\
\hline 4 & 18 & 0,8267 & $-0,9092$ & 0,468 & 0,590 & $\begin{array}{c}\text { Significant } \\
\text { for } \alpha=1 \%\end{array}$ \\
\hline 5 & 44 & 0,9083 & $-0,9530$ & 0,304 & 0,393 & $\begin{array}{c}\text { Significant } \\
\text { for } \alpha=1 \%\end{array}$ \\
\hline 6 & 41 & 0,8835 & $-0,9399$ & 0,312 & 0,403 & $\begin{array}{c}\text { Significant } \\
\text { for } \alpha=1 \%\end{array}$ \\
\hline
\end{tabular}

Table 8. The value of $\mathrm{K}_{3}$ in sediment samples.

\begin{tabular}{|c|c|}
\hline No. & $\begin{array}{c}\mathrm{K}_{3} @ 20^{\circ} \mathrm{C} \\
\mathrm{m}^{-1}\end{array}$ \\
\hline 1 & 12,4028 \\
\hline 2 & 11,2640 \\
\hline 3 & 10,9970 \\
\hline 4 & 8,6537 \\
\hline 5 & 11,2713 \\
\hline 6 & 10,8544 \\
\hline
\end{tabular}


Empirical calculation of $\mathrm{K}_{3}$ values conducted in this research shows the value of $\mathrm{K}_{3}$ had an inversely proportional relationship to the SOD value in sediment and was directly proportional to the rate of decrement in DO (indicated by the value of the gradient of DO concentration). This relationship is an auto-correlation obtained from the equation to calculate the value of $\mathrm{K}_{3}$. Further research using a variation of the SOD value will reaffirm the statement. However, factors that affect the magnitude of the value $\mathrm{K}_{3}$ cannot yet to be analysed with certainty. Therefore, further research needs to be conducted about the factors that affect $\mathrm{K}_{3}$ value in the sediment.

Recapitulation of the SOD and $\mathrm{K}_{3}$ value based on sedimentary soil texture shows in Table 9.

Table 9. Recapitulation of the SOD value and $\mathrm{K}_{3}$ based on sediment texture.

\begin{tabular}{|c|c|c|c|}
\hline No. & $\begin{array}{c}\text { SOD } @ 20^{\circ} \mathrm{C} \\
\mathrm{g} / \mathrm{m}^{2} / \mathrm{day}\end{array}$ & $\begin{array}{c}\mathrm{K}_{3} @ 20^{\circ} \mathrm{C} \\
\mathrm{m}^{-1}\end{array}$ & $\begin{array}{c}\text { Soil Texture } \\
\text { Class }\end{array}$ \\
\hline 1 & 0,5805 & 12,4028 & silt loam \\
\hline 2 & 0,3835 & 11,2640 & silty clay loam \\
\hline 3 & 0,3143 & 10,9970 & silt loam \\
\hline 4 & 0,8487 & 8,6537 & silty clay loam \\
\hline 5 & 0,2427 & 11,2713 & sand \\
\hline 6 & 0,3317 & 10,8544 & silty clay loam \\
\hline
\end{tabular}

\subsection{The Implication of SOD Value}

The presence value of SOD in the sediment showed that the consumption of DO in the water is not only derived from BOD (biochemical oxygen demand) and COD (chemical oxygen demand) that have suspended or dissolved phase, either for natural or artificial channel channels. The consumption of DO will still occur in the channel that has huge amount of sediment although the polluters with the high BOD and/or COD rate have been stopped. Therefore, the management of disposed wastewater is not enough to revitalise the watercourse and improve its water quality. The good management of sediments must also be established to give an effective result of channel revitalization and the water quality of the watercourse can remain good.

There are several methods in managing sediment in the channel. One of them is to build an aeration structure that allows sediment particles to accumulate so they can be removed, either manually or automatically. Another option is an aeration structure that facilitates sediment particles to dissolve into water as dissolve or suspended organic compounds, so the removal process can be done by using a same method as removing BOD or COD in the water.

\section{Conclusion}

The existence value of SOD in the open channel was indicated by the carrier flow regime. Heterogeneous flow regime showed a concentration of solids in the bottom of the channels that can form a sediment bed and therefore the oxygen consumption. In addition, sediment that categorised as clay and/or silt (indicated by small particle diameter, low density, and high percentage of water content) and a high degradable organic content can increase value of SOD in the sediment.

\section{Nomenclature}

$\mathrm{C}_{\mathrm{d}}=$ discharge coefficient

$\mathrm{d}=$ particle diameter, selected diameter cut size $\left(\mathrm{d}_{50}\right)$

$\mathrm{g}=$ gravitational acceleration, $\mathrm{m} / \mathrm{s}^{2}$

$\rho_{\mathrm{p}} \quad=$ sediment particle density, $\mathrm{kg} / \mathrm{m}^{3}$

$\rho_{\mathrm{w}} \quad=$ water density, $\mathrm{kg} / \mathrm{m}^{3}$

$\mathrm{C}_{\mathrm{D}} \quad=$ drag coefficient

$\mathrm{D}=$ channel diameter, $\mathrm{m}$

$\mathrm{F}_{\mathrm{LD}} \quad=$ limit factor of deposition velocity

$\mathrm{V}_{\mathrm{LD}}=$ limit velocity of particle deposition, $\mathrm{m} / \mathrm{s}$

$\mathrm{v}_{\mathrm{LH}}=$ limit velocity of homogenous flow, $\mathrm{m} / \mathrm{s}$

$(\mathrm{SOD})_{20}=$ the number of sediment oxygen demand (SOD) flux at $20^{\circ} \mathrm{C}, \mathrm{mg} / \mathrm{m}^{2} /$ day

$(\mathrm{SOD})_{\mathrm{T}}=$ the number of sediment oxygen demand (SOD) flux at $\mathrm{T}^{\circ} \mathrm{C}, \mathrm{mg} / \mathrm{m}^{2} /$ day

$\mathrm{A}=$ cross-sectional area of overlying water, $\mathrm{m}^{2}$

$\mathrm{C}_{\mathrm{f}}=\mathrm{DO}$ concentration at the end of measurement, $\mathrm{mg} / \mathrm{L}$

$\mathrm{C}_{\mathrm{i}}=\mathrm{DO}$ concentration at the beginning of the measurement, $\mathrm{mg} / \mathrm{L}$

$\mathrm{T}=$ average testing temperature, ${ }^{\circ} \mathrm{C}$

$\mathrm{V}=$ overlying water volume, $\mathrm{m}^{3}$

$\theta=$ temperature constant $=1,065$

$\mathrm{C}_{\text {final }}=\mathrm{DO}$ concentration at $\mathrm{t}$ (calculated based on the regression equation), $\mathrm{mg} / \mathrm{m}^{3}$

$\mathrm{C}_{\text {initial }}=\mathrm{DO}$ concentration at $\mathrm{t}_{\mathrm{o}}$ (calculated based on the regression equation), $\mathrm{mg} / \mathrm{m}^{3}$

$\mathrm{K}_{3}=$ deoxygenation coefficient due to SOD, $\mathrm{m}^{-1}$

SOD $=$ the number of sediment oxygen demand (SOD) flux, $\mathrm{mg} / \mathrm{m}^{2} /$ day

Authors would like to express their gratitude to Institut Teknologi Bandung (ITB) who had provided financial support in this research through P3MI programme (Program Penelitian Pengabdian Masyarakat).

\section{References}

1 M. Barcelona and W. Wang, Usefulness of Sediment Oxygen Demand as a Tool for Impoundment Management (Water Resources Center, Univ. of Illinois, 1982)

2 C.R. Ellis and H.G. Stefan, Wat. Res. Bull. 25, 11691176 (1989)

3 R. Giguère, L. Fradette, D. Mignon and P. Tanguy, J. Chem. Eng. Rsch. Dsgn., 943-950 (2009)

4 K.Y.H. Gin and A.P. Gopalakrishnan, J. Env. Eng. 136, 78-85 (2010)

5 K. Hatcher, Sediment Component of Oxygen Demand in Streams (Institute of Natural Resources, University of Georgia, Athens, 1980) 
6 C.B. Price, C. Cerco and D. Gunnison, Sediment Oxygen Demand and Its Effects on Dissolved Oxygen Concentration and Nutrient Release: Initial Laboratory Studies (U.S. Army Corps of Engineers, Washington DC, 1994)

7 T.A. MacPherson, Sediment Oxygen Demand and Biochemical Oxygen Demand: Patterns of Oxygen Depletion in Tidal Creek Sites (University of North Carolina, 2003)

8 S. Rounds and M. Doyle, Sediment Oxygen Demand in the Tualatin River Basin, Oregon (U.S. Geological Survey Water Resources Investigations, 1997)

9 T. Seiki, H.Izawa, E. Date and H. Sunahara, Wat. Rsch. 28, 385-393 (1994) 